\title{
Aus einem Schreiben von Hrn. L. Ćruls, Vicedirector der Sternwarte zu Rio de Janeiro, an den Herausgeber. (Betr. den Cometen 1883 II.)
}

J'ai reçu le télegramme annonçant la découverte faite à Melboume d'une comète le 16 Janvier; ce jour-là, le ciel étant couvert, il a été impossible de trouver l'astre. Le lendemain, I7, après quelques minutes de recherches, j'ai retrouvé la comète, dont le déplacement etait assez considérable, surtout en Ascension droite ${ }^{*}$ ). Nous avons continué de l'observer pendant plusieurs nuits de suite, mais les positions n'étant pas encore réduites, je suis obligé de remettre à plus tard l'envoi des positions de la cométe. Pour le moment, je ne vous transmets que les notes suivantes copiées du Registre d'observations.

-) Das Telegramm aus Melbourne gab die Rectascension des Cometen sehr fehlerhaft an: $22^{\mathrm{h}} 4^{\mathrm{O}^{\mathrm{m}}}$ statt $22^{\mathrm{h}} 4^{\mathrm{mm}}$. $K r$.
I 884 Janvier I 7. - Noyau présentant l'aspect d'une belle nébulosité circulaire, avec condensation vers le centre. On distingue la queue, mais assez pâle.

Le spectre présente les trois bandes des hydrocarbures, pâles et estompées.

Janvier I 8 . - Noyau lumineux, queue $11^{\circ}$, étalée mais limitée à droite (image renversée) par un filet rectiligne plus lumineux. (En tenant compte du sens du mouvement de la comète, il est à remarquer que le bord plus net et mieux défini, est celui du côté $\mathrm{s} u \mathrm{~d}$, direction vers laquelle se déplace l'astre. J'ai noté la même particularité pour la grande comète australe de 1882 .)

Les 24 et 25 Janvier l'aspect général était le même, ainsi que le spectre; l'intensité lumineuse était cependant affaiblie.

Rio de Janeiro 1884 Mai 6.

\section{Cruls.}

\section{Bestimmung der Länge von Upsala.}

Im Monat April und Mai ${ }_{188}$ ist eine telegraphische Längenbestimmung zwischen Stockholm und Upsala von mir und dem Assistenten an der Sternivarte zu Stockholm, dem Candidaten der Philosophie Larsén, in zwölf Beobachtungsnächten ausgefuihrt worden.

Als Resultat derselben, auf den Meridiankreiş der Sternwarte in Stockholm und auf das Centrum der Sternwarte in Upsala reducirt, hat sich ergeben:

Stockholm östlich von Upsala: ${ }^{\mathrm{m}} 43^{\mathrm{s}} 79^{6} \pm 0.020$.

Stockholm 1884 Mai 25.
Diese Längendifferenz weicht nur um ośro von der früher angenommenen $a b$.

Wenn man nun sowohl das Resultat der im Jahre I 870 von Fuss und Nyrén zwischen Stockholm und Helsingfors ausgeführten Längenbestimmung, als auch die bekannte Längendifferenz Helsingfors - Greenwich dazu fügt, so wird man endlich erhalten:

Die Längendifferenz $z w$ ischen Upsala und Greenwich $=$ I $^{\mathrm{h}} \mathrm{ro}^{\mathrm{m}} 30^{\mathrm{s}} \mathrm{rg}$.

\section{Muthmassliche Auffindung des Cometen 1858 III.}

Die Centralstelle erhielt gestern folgendes Telegramm aus Wien:

จAssistent Spitaler sucht mit grossem Refractor $185^{8}$ Schulhof Comet. Schwacher Nebel vom 2 26. Mai AR. $=265^{\circ}$ I $^{\prime} \mathrm{PD}$. $=54^{\circ} 28^{\prime}$ fehlte bei gestriger Revision.

Weiss."

welches in etwas abgekürzter Fassung sofort weiter gegeben wurde. Die angegebene Position des vermissten Nebels voin 26. Mai: $\alpha=265^{\circ}$ I $\mathbf{2}^{\prime} \delta=+35^{\circ} \mathbf{3 2}^{\prime}$ stimmt auffallend genau mit Herrn L. Schulhof's Aufsuchungs-Ephemeride in Nr. 2590, wenn man in dieselbe mit dem Argument Länge der Sonne für Mai $265=66^{\circ}$ und wahre Anomalie des Cometen $=+49^{\circ} \circ$ eingeht. Die Lichtstärke würde seit Mai 26 bedeutend abgenommen haben.

Kiel 1884 Juni 20.

$K r$.

Nachtrag. Am 22. Juni Vormittags telegraphirte Professor Weiss aus Wien:

-Nach Object vom 26. Mai am 20. Juni im Anschluss an eine Ephemeride gesucht und Platz leer -gefunden.

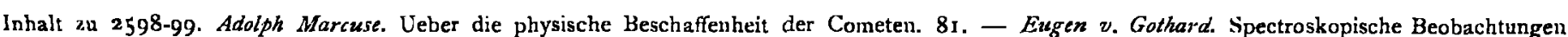
des Cometen I884 I (Pons I8I2). 99. - H. C. Wilson. Observations of Comet I884 I (Pons I8I 2). IO5. - G. Celoria. Cometa del 1433. I09. - $N$. Ekholm. Verzeichniss von Mondculminationen und Mondsternen. Io9. - L. Cruls. Aus einem Scbreiben an den Herausgeber. II I. - P. G. Rosén. Bestimmung der Iäinge von Upsala. I1I. - Muthmassliche Auffindung des Cometen 1858 III. I I I. 